Original Research Paper

\title{
Factors Influencing Team Effectiveness in Higher Education
}

\author{
Jeffrey Lawrence D'Silva and Seyedali Ahrari \\ Institute for Social Science Studies, Universiti Putra Malaysia, 43400 UPM Serdang, Selangor, Malaysia
}

Article history

Received: 03-08-2016

Revised: 09-09-2016

Accepted: 10-09-2016

Corresponding Author: Jeffrey Lawrence D'Silva Institute for Social Science Studies, Universiti Putra Malaysia, 43400, Serdang, Selangor, Malaysia

Tel: +60133615327

Email: jld@upm.edu.my

\begin{abstract}
Organizations must fulfill in order to produce and sustain effective teams. Many factors can affect how effectively teams perform. Thus, this study offers the results of an investigation of the factors that donate to team effectiveness in higher education. Task interdependence, task conflict and personality traits appeared as key influences on team effectiveness. An overall of 275 randomly selected researchers from local Malaysian universities. The results were measured by the Structural Equation Modeling (SEM) analysis. The empirical results showed task interdependence was found to be a critical factor in team effectiveness. Thus, task interdependence that emerged in this study offers a significant influence on the works on team effectiveness in professional contexts.
\end{abstract}

Keywords: Task Interdependence, Task Conflict, Personality, Team Effectiveness, Higher Education

\section{Introduction}

Teams and groups in the place of work are not a novel phenomenon. Casually and officially they have occurred for a number of years as organizations explore for best methods to advance their total efficiency; no subject has gathered more attention in recent years as an option than that of teams. The word team mentions to a collection of individuals with complementary skills and generates synergy needed to finish a job, duty, or project. Currently, the subject of teamwork and collaboration gain importance because of the cumulative stress and pressure on institutions to complete their tasks with more efficient outcomes. The fact that team-work has become an equally important subject in most educational and organizational settings in their research and development programs (Gabelica et al., 2012). This is mainly understandable in study institutions such as universities and colleges, where the difficulty and variety of their investigation teams construct teamwork and collaboration a requirement.

Unfortunately, many higher institutions are not prepared to fully embrace teamwork and teams. The rise of teamwork in the university is supposed to affect an amplify in the faculty duties and responsibilities, redeployment in the influence and power of teaching staff or associates and a rearrangement of team's workload (Adams, 1999). Adams (2001) also argued that the culture of higher institution further recommend that teams involved with these persons will not complete the task well and may not be well accepted in the academy. The ultimate success of teams (e.g., research groups) is not simply limited to the associates' aptitudes and assets, but also the communicating kind of team associates, which are intensely, controlled by the features of the separate team members (Bradley et al., 2013). As a result, teamwork capability development should be effectively integrated into higher education degree programs, which should comprise of planned activities that develop researchers' capability to work in teams effectively. Many degree programs should take into account the different factors that inspire the development of effective teamwork skills in researchers in professional environments.

Recently, though, there has been increased attention in key cognitive and affective variables and their correlation to teamwork behaviors and subsequent performance (Arthur et al., 2005; Marks et al., 2000; Sander et al., 2015). There are few studies that cover this subject in educational environments and the ones that do typically mention to certain factors (Curşeu and Pluut, 2013; Koh and Lim, 2012; Wanous et al., 2009). These studies have proposed several variables such as task conflict, task interdependence and the personality traits, in several theories of team behavior and functioning. Thus, the aim of this study is to study whether these three factors act as enablers of team effectiveness in higher education institutions.

\section{Theoretical Background}

\section{Task Interdependence and Team Effectiveness}

Task effectiveness is thought to be precipitated by certain organizational structure factors, including task 
interdependence. Excellent teams build on interdependency and task-determined contact between team members. Task interdependence is a basic form of interdependence that functions simultaneously in a team. Knowledge or perceptions of task interdependence is defined as a team member's perception of the degree to which effective team functioning needs the individual to act with team associates so as to complete a certain task or obtain a certain output (Arthur et al., 2005; Edwards et al., 2006). Van der Vegt et al. (2001) suggest that task interdependence upsurges when task itself becomes challenging and team members need a greater degree of support from each other in terms of, for example, resources, info or skill. It defines the degree to which a task needs teamwork and shared action and has described effects on group effectiveness.

Evidence from several studies suggests that task interdependence directly improved team effectiveness and performance compared to doing the task alone, mostly for concept mastery tasks, problem-solving and decision making (Molleman, 2009; Van Der Vegt et al., 2005). For instance, a previous analysis has discovered a significant correlation between task interdependence and job approval and satisfaction (Van der Vegt and Van de Vliert, 2002). Another study from Hambrick et al. (2015) showed that complex interdependence was significantly related to task-performing groups and to task strategy. Similarly, Kirkman et al. (2011) used organizational groups of repetition in an American-based mining and minerals administering company to examine team organization and found that member task interdependence to be significantly linked to a career performance. Other findings investigative the effect of task interdependence on accomplishment, mainly relating to university students and grown-ups in a diversity of contexts (Alavi and McCormick, 2008; Aubé et al., 2009; Langfred, 2007; Somech, 2008; Somech et al., 2009).

It follows from the findings of these studies that the link between team performances is affected by the mutual interaction among team members. However, in spite of the research proof for this fully recognized correlation amid interdependence and team performance, there is yet a lot that is unidentified about the interface procedure among team members in professional settings like universities, though evidence appears to explain a crucial role of process-related behavior in the correlation among task interdependence and team effectiveness (Wageman, 1995).

\section{Task Conflict and Team Effectiveness}

Teams face the challenge of staying creative and productive in investigation and growth institutions like the institution of higher education in which conflict may be present involving task conflict between team members. In fact that conflict about the distribution of materials, processes, decisions and interpretation of data appears to be unavoidable in the team procedure in that the members of teams are frequently from a varied background with diverse abilities, information and knowledge. Barki and Hartwick (2004) defined task conflict as a cognitive conflict, refers to the focal point of disagreement/conflict between team members about judgments, beliefs, thoughts and feelings and as potentially consist of disagreement about the finest technique to accomplish the team's task. Generally, task conflict is attributed to the condition rather than to the relationships of team members (Bono et al., 2002).

For decades scholars have tried to investigate the impacts of task conflict on team effectiveness elements (e.g., performance satisfaction) (e.g., Balkundi and Harrison, 2006; Cohen et al., 1996; Harrison et al., 2002). Results regarding the influences of task conflict on team performance and outcome have been slightly mixed. Certain scholars have discovered the adverse influence of task conflict on team functioning (Troth et al., 2012), while others display positive effects particularly in tasks' group that need significant reasoning effort. Sarason (1984) argued that conflict tends to deliver negative feeling and reduce productivity and satisfaction in teams; so, it also obstructs cognition behavior. When team members consider complications, they ignore key evidence and facts. In circumstances of conflict, team members hide aggression. They do not swap info and they cannot pay attention to others' ideas. On the other hand, studies by Jehn and Chatman (2000) displayed that groups can increase decision quality as diverse thoughts are resolved openly. Jehn (1995) proposed that task conflict can have a significant influence on institutional effectiveness since a procedure of discussions and disagreements between team members augments the quality of decision-making in the teams. Once intellectual conflict happens in teams, the interface between team members upsurges and assists teams resolve problems (Jehn, 1995). As stated by Putnam (1994), task conflict assists members of team interconnect with each other in groups about possible difficulties, simplify confusions and share material and knowledge.

Supporting the negative correlation view, previous research shows that task conflict decreases overall team effectiveness (De Dreu, 2014). Their study reported a 0.23 meta-analytic relationship between these factors. This result embraces that task conflict raises strain and tension, which, sequentially, obstruct with task performance. Commonly, however, some empirical studies have established positive results of task conflict, especially for group effectiveness (e.g., Jehn, 1997; Shah and Jehn, 1993). There is general evidence in relation to the fact that task conflict has both negative and significant influences on team performance (Puck and Pregernig, 2014), though it deals with the queries of how and why it effects on performance is still not fully understood. 


\section{Personality and Team Effectiveness}

Majority findings recognized personality traits as highly relevant in effective team performance (Hogan and Holland, 2003; Sackett and Walmsley, 2014). Most definitions of personality traits tend to refer to the entire mental system human being at any step of his development. It accepts every step of human personality: Motives, skill, morality, emotions, thoughts and other main areas of psychological function that has been built up in conscious mental life (Behera and Bhardwaj, 2015). Kinicki (2007) defines personality characteristics as a set of personalities that are accountable for an individual's individuality and the central element of diversity are powerfully motivate our arrogances, hopes and norms about other people, therefore affecting our performance. Furthermore, five dimensions of personality characteristics are identified as the big five, identified by Colquitt et al. (2009), these include; extraversion, openness to experience, neuroticism, conscientiousness and agreeableness.

In numerous investigations addressing the linkage among personality characteristics and team performance, Barrick and Mount (1991) applied meta-analysis to examine the validity of the personality factors through five different occupational categories. The results of this analysis specified that conscientiousness and extraversion were effective traits of team performance in all occupational teams with valued correlations of 0.22 and 0.13 , respectively. This meta-analysis study also discovered that reliability is the most consistent factor of team performance across a function of occupational and criterion types. Similarly, other studies personality traits like conscientiousness and emotional stability (i.e., neuroticism) can eventually serve vital roles in team performance (e.g., Salgado, 1997). Kichuk and Wiesner (1998) argue that personality characteristics can eventually have a direct effect on performances by predicting the performance skills of the persons in a team, categorizing the persons able to function as a part of teamwork and clarifying "best combinations" of individuals in teams to improve team performance and outcome. In the present paper, we supposed to examine the results of past studies concerning the relations between personality traits and team effectiveness in different settings.

\section{Hypothesis Development}

Base on the literature review, the present study investigated three hypotheses:

- Hypothesis 1: A positive relationship can be observed between task interdependence and team effectiveness among university researchers.

- Hypothesis 2: A relationship can be observed between task conflict and team effectiveness among university researchers.
- Hypothesis 3: A positive relationship can be observed between personality and team effectiveness among university researchers.

\section{Methodology}

The present work employed quantitative techniques via a survey questionnaire. An overall of 275 researchers were randomly selected from local Malaysian universities. For Structural Equation Modeling (SEM) studies, Kline (2010) proposed that 200 or more participants would be appropriate and Ho (2006) repeated that in SEM sample size must be sufficiently large. For this study, 275 samples meet the condition of SEM (Markus, 2012). The data were analyzed by AMOS software. The data analysis was parted into two portions: (1) descriptive data (i.e., frequency, percentage, means and Standard Deviation (SD)) was employed to portray the patterns of the data and constructs of the study; and (2) a Structural Equation Modeling (SEM) was used the study suggested hypotheses. The research used available for each construct including Personality (BFI; John and Srivastava, 1999), Task effectiveness survey (Hackman, 1990), Task interdependence (Van Der Vegt et al., 2001) and Task conflict in this study was most frequently measured with an instrument advanced by Jehn (1994; 1995). The questionnaire was the enhanced for Malaysian context via a series of instrument development consultations. This model was initially comprised of 61 self-replied items that assessed TI (12 items), TC (8 items), P (30 items) and TE (11 items) employed a five-point Likert scale to measure answers to each query. The outcomes of the data analysis abridged respondents' reports and descriptive statistics. Confirmatory Factor Analysis (CFA) is used with the intention of examining the reliability and validity of the measurement model, selection four variables. The path model is inspected with the suggested model postulating support to three hypotheses. SEM is employed to test the structural path model.

\section{Demographic Profile of Respondents}

With regards to gender, out of 275 participants, $129(46.9 \%)$ were male, while the other 146 participants (53.1\%) were female. Above all, the findings revealed that Malaysian females are more possible than males to participate in universities as researchers. For the age, the mainstream of the researchers was ranged between 25 to 35 years old (n $=135,49.1 \%$ ), while the minority of them were 56 years old and above $(\mathrm{n}=28,10.2 \%)$. The mean age of participants who joined in the study was 39 years $(S D$ $=10.235)$. In the case of the race of respondents, the majority of respondents were Malay $(\mathrm{n}=186,67.6 \%)$, followed by Bumiputeras from Sabah and Sarawak (n 
$=37,13.5 \%)$. With regards to educational level, 197 respondents $(71.6 \%)$ had $\mathrm{PhD}$. In terms of the mean score of years of employed in a university, the average year is $9.9(S D=10.037)$. In terms of being a research project leader, the majority of them $(60.4 \%)$ had led 1-5 research projects. Finally, the results showed that majority of respondents $(65.5 \%)$ were a member in 5 to 10 research projects teams.

\section{Structural Equation Modeling (SEM)}

SEM is a multivariate technique that can be explained as a path analysis (Hu and Bentler, 1999). Moreover, while traditional multivariate techniques are unable of gauging measurement error, SEM generates absolute estimates of the measurement error. Lastly, while the conventional multivariate methods depend merely on practical measurements, SEM can relate both unobserved (latent) and observed (manifest) constructs (Byrne, 2010). SEM is confirmatory instead of an exploratory technique of data analysis, which is suitable for this investigation. The estimation method used in this is called Maximum Likelihood Approach, which adopts multivariate normal data and a reasonable sample size, e.g., about 275 observations. SEM is functioned in the present paper in two phases of latent path modeling (Byrne, 2006; Hancock and Mueller, 2004). Primary, we prove the adequacy of the construct validity of every separate construct and measurement model of the investigation through CFA. Second, we evaluate the structural model to reveal the correlation between the independent and dependent constructs. By analyzing data, we reflect normality by utilizing the maximum likelihood in SEM. As stated by Byrne (2010), data is measured to be normal if skewness is between -2 and +2 and kurtosis between -3 and +3 . The outcome of the assessment of normality in the measurement model showed that the data was normally distributed. On the word of skewness and kurtosis standards, the findings show no item to be non-normal. Skewness was ranged from -1.002 to 0.412 and kurtosis was ranged from 0.684 to 1.753 .

\section{Measurement Model}

In a trustworthy technique, the measurement model was confirmed to demonstrate that nominated items repeat the unobserved variables (Hair et al., 2013). The CFA outcome showed an adequate measurement model with high factor loadings for entire items on the predictable factors and communalities of each item surpassing 0.50 . This indicates that all the variables reproduce the convergent construct validity estimation. As revealed in Table 1, the number of items for each construct is as follows: TI ( 3 items), TC ( 3 items), P (7 items) and TE (3 items); a total of 16 items are remaining. For content validity in SEM, remaining factors are above 0.70 for all items (Fig. 1). For the entire variables, Construct Reliabilities (CR) for all scales are bigger than 0.80 and AVE is bigger than 0.50 , as the value of AVE must be upper than 0.50 to assume convergent validity. All AVE values were bigger than the values of the squared correlations, revealing the high discriminant validity of every variable from other variables.

There are many fit indices that characterize the overall fit between the covariance matrices in SEM. Generally asserted indices cast-off (Chau and $\mathrm{Hu}, 2001$ ) will be selected to measure the model fit for the present research. These indices can be appropriately appointed to assess absolute model fit by correlating predictedversus-observed variances and covariances, to add a consequence role for lack of parsimony and to associate the absolute fit of the model to an alternative model on the data. Fit indices comprise the chi-square test, the GFI and the standardized root means square residual. As presented in Table 2, the model shows a statistically significant chi-square of $745.102(d f=316, \mathrm{p}=0.000)$, with $p$-value better than the proposed level of 0.05 , showing a very suitable model fit to the data. The relative chi-square was 2.358 , inside the proposed level of $<5.0$ (Hu and Bentler, 1999). The fit of the model to the data can also be assessed by GFI in addition to AGFI. In the present work, AGFI is 0.872 and NFI are 0.877 , both smaller than the thresholds $(>=0.9)$ for these two indices.

Furthermore, RMSEA values of lower than 0.08 designates adequate model fit, while less than 0.05 designates good model fit (Byrne, 2010). The RMSEA in this research is 0.070 , revealing an acceptable fit in the population. Besides RMSEA, the CFI $=0.924$, the TLI $=$ 0.907 and IFI $=0.925$ proposes suitable model fit, while the levels for these two indices are more than 0.9. Table 3 also displays that the relationships among variables ranged from 0.007 to 0.47 .

\section{Structural Model and Hypothesis Tests}

Similarly, as formerly stated, with the aim of confirming the direct contribution of every construct of independent variables added in the equation concerning their dependent counterpart, SEM has been utilized. The outcomes of evaluating the structural model fit for the direct model showed a model fit to the data: $\chi^{2}(98)=230.605, \mathrm{p}=0.000$, $\chi 2 / \mathrm{DF}=2.353 ;$ GFI $=0.908, \mathrm{AGFI}=0.872, \mathrm{CFI}=$ $0.924, \mathrm{NFI}=0.877, \mathrm{TLI}=0.907, \mathrm{IFI}=0.925$. The fit indices of the structure model showed that the GFI, CFI, TLI and IFI come meaningfully close or go over its cutoff value (0.9). Furthermore, the RMSEA was 0.07 , which is between 0.03 and 0.08 . Figure 1 shows that the three constructs TI, TC and P mutually describe $24 \%$ variance in TE. 


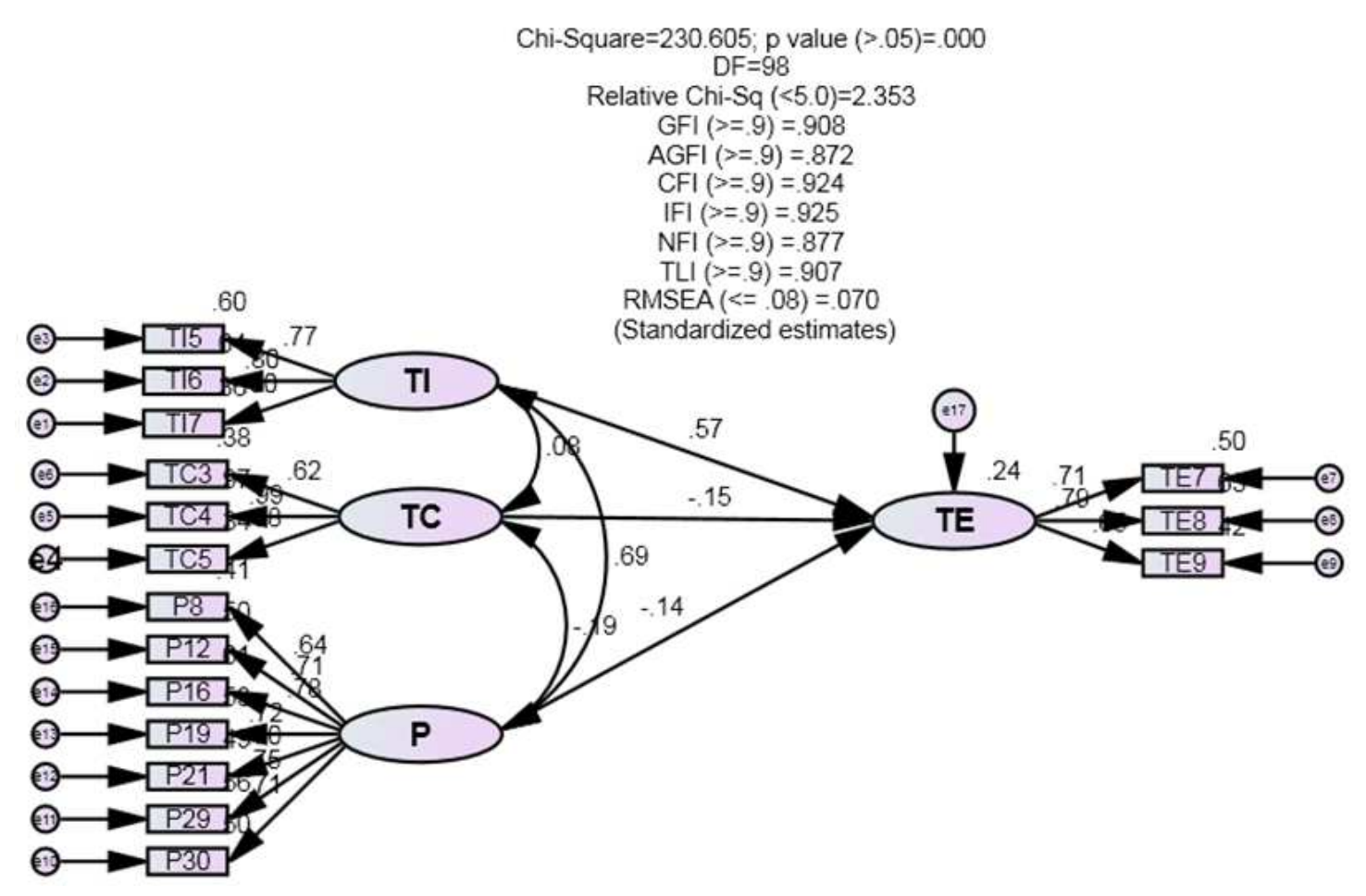

Fig. 1. The full direct structural equation model of team effectiveness with standardized coefficients. Note: Task interdependence (TI); Task conflict (TC); Personality (P) and Team effectiveness (TE). For all estimates ${ }^{*} p<0.05 . * * p<0.01,{ }^{* * *} p<0.001$.

Table 1. Average Variance Extracted (AVE) and Construct Reliability (CR) of study instruments

\begin{tabular}{llllll}
\hline Construct & Original no. of items & Final no. of items & AVE & Initial Reliability & CR \\
\hline Task interdependence & 12 & 3 & 0.50 & 0.860 & 0.831 \\
Task conflict & 8 & 3 & 0.563 & 0.888 & 0.835 \\
Personality & 30 & 7 & 0.504 & 0.881 & 0.901 \\
Team effectiveness & 11 & 3 & 0.527 & 0.841 & 0.815 \\
\hline
\end{tabular}

Table 2. Model-of-fit estimation of the research model

\begin{tabular}{llll}
\hline Fit indices & Threshold value & Sources & Outcomes achieved \\
\hline Relative Chi-Square (CMIN/DF) & $<5.0$ & Hu and Bentler (1999) & 2.353 \\
Goodness-of-Fit Index (GFI) & $>=0.9$ & Browne (1984) & 0.908 \\
Adjusted goodness-of-fit index (AGFI) & $>=0.9$ & Chau (1997) & 0.872 \\
Comparative Fit Index (CFI) & $>=0.9$ & Kline (2005) & 0.924 \\
Tucker-Lewis Index (TLI) & $>=0.9$ & Hu and Bentler (1999) & 0.907 \\
Incremental Fit Index (IFI) & $>=0.9$ & Hu and Bentler (1999) & 0.925 \\
Normal Fit Index (NFI) & $>=0.9$ & Hu and Bentler (1999) & 0.877 \\
Root Mean Square Error of Approximation (RMSEA) & $<0.08$ & Byrne (2010) & 0.070 \\
\hline
\end{tabular}

Table 3. Presenting squared correlation coefficients $\left(\mathrm{R}^{2}\right)$ for study instrument, $t$ value, Mean and standard deviation of the study

\begin{tabular}{llllllll}
\hline Construct & $t$ & TE & P & TC & TI & Mean & $S D$ \\
\hline Team effectiveness & 2.90 & 1 & & & & 3.88 & 0.524 \\
Personality & 2.44 & 0.077 & 1 & & & 3.79 & 0.405 \\
Task conflict & -.176 & 0.005 & 0.034 & 1 & & 2.43 & 0.697 \\
Task interdependence & 0.363 & 0.213 & 0.470 & 0.007 & 1 & 3.64 & 0.557 \\
\hline
\end{tabular}

Table 4. Descriptive data of constructs

\begin{tabular}{llr}
\hline Constructs & Mean & $S D$ \\
\hline Task interdependence & 3.641 & 0.557 \\
Task conflict & 2.437 & 0.697 \\
Personality & 3.799 & 0.405 \\
Team effectiveness & 3.883 & 0.524 \\
\hline
\end{tabular}


Table 5. The direct hypothesised model: Unstandardized and standardised regression weights

\begin{tabular}{lllllllll}
\hline Hypotheses & Correlations & B & S.E & Beta & C.R & $P$-value & Statue & Evidence \\
\hline H1 & TI $\rightarrow$ TE & 0.756 & 0.183 & 0.571 & 4.135 & $* * *$ & Sig. & Supported \\
H2 & TC $\rightarrow$ TE & -0.145 & 0.074 & -0.146 & -1.948 & 0.051 & No-sig. & Rejected \\
H3 & $\mathrm{P} \rightarrow$ TE & -0.173 & 0.149 & -0.141 & -1.164 & 0.245 & No-sig. & Rejected \\
\hline
\end{tabular}

Note: $\mathrm{TI}=$ Task interdependence; $\mathrm{TC}=$ Task conflict, $\mathrm{P}=$ Personality; and TE $=$ Team effectiveness.

For all estimates ${ }^{*} p<0.05$. $^{* *} p<0.01,{ }^{* * *} p<0.001$.

Along with SEM investigation, the direct association among the independent constructs and dependent construct will be examined under certain hypotheses: (H1) TI will have a significant influence on researchers' TE in higher educational institutions. (H2) TC will have a significant effect on researchers' TE in higher educational institutions. (H3) $\mathrm{P}$ will have a significant effect on researchers' TE in higher educational institutions.

\section{Results}

\section{Descriptive Statistics of Constructs}

Table 4 exposes averages and $S D$ s for all four variables, three independent (TC, TI and P) and one dependent (TE). The results showed that for the participants, $\mathrm{P}$ is significantly above mean (mean = 3.799, $S D=0.405)$, while TE seems to be little higher $($ mean $=3.883, S D=0.524)$. The outcome also presented that the mean score of task interdependence predict the effectiveness in team quit high among researchers (Mean $=3.641, S D=0.557$ ).

\section{Discussion}

The result of the structural model, the research discovered that the TI latent construct had a positive impact on the TE $(\beta=0.571$, C.R. $=4.135, \mathrm{Sig}=0.000)$. Therefore, $\mathrm{H} 1$ was supported regarding there being a significant positive association between TI with TE. The results of our study were shown to be in line with the work of Wageman and Baker (1997) who uncovered that with better team interdependence will be more effective. Allen and Hecht (2004) showed that performance of task effectiveness arises from the associations shaped over the reciprocal interdependence of team members.In addition, our results in this study proposed that task interdependence is affected by persons' trust in the capability of teams to achieve work more efficiently than when persons function lonely.

On the other hand, based on Table 5, revealed that TC had no direct significant association with TE. The standardized path coefficient presented that the data were not consistent with the hypothesis by showing a nonsignificant association $(\beta=-0.146$, C.R. $=-1.948, p=$ $0.051)$ among the TC and TE. The results of our study were shown to be inconsistent with those of Bradley et al. (2012) findings that TC positively affects TE in a high psychological safety climate. According to Lee et al. (2014), TE is a key factor success in team work in organizations. Prior research (e.g., Jehn, 1994; 1995; 1997) has also shown that only when situations are ripe for high levels of task-oriented conflict (i.e., disagreements about views, thoughts, ideas related to the task) can they improve a team's consequence.

Furthermore, the study did not find adequate proof to support the hypothesis that $\mathrm{P}$ positively advanced TE in higher educational institutes $(\beta=-0.141$, C.R. $=-1.164$, $\mathrm{p}=0.245)$. Accordingly, $\mathrm{H} 2$ and $\mathrm{H} 3$ were rejected. Colquitt et al. (2009) stated that ineffective teams may be the result of unfitting team members' personality arrangement. However, a prior study has revealed (Barrick et al., 1998) that organizations must constitute their teams with persons who display acceptable levels of care and sociability, as this will donate positively to task cohesion and team performance.

\section{Conclusion}

The objective of this research was to investigate which factors can be considered to be enablers of team effectiveness in educational settings. This study determined three factors namely task conflict, task interdependence and the personality traits as key influences on of team effectiveness as supported by the literature. The findings suggested that task interdependence is positively connected with team effectiveness. However, the connection between task conflict and the personality traits and team effectiveness did not appear among Malaysian participants. In addition, our study did not found any associations among task conflict and team effectiveness outcomes. However, previous studies find that association conflict plays a vital shared role in these relations and that the effects differ across satisfaction and performance outcomes.

\section{Implications}

We consider that the current research in higher education creates numerous noteworthy suggestions for training and growth. The outcomes of the current work treat task interdependence as an important variable and combine it with the team effectiveness model. The findings of this research propose that administrators of Malaysian universities must improve task interdependence, as it encourages team collaboration. 
High task interdependence in teams directs to collaboration, information sharing and other cooperative actions between team members to finish tasks. To ensure a cooperative working place, the higher institution must relate to team-work based on task interdependence. Researchers must have reliable information systems that allow them to make queries as well as manage and organize their team. There must be a distribution of roles and tasks among team members, as this practice facilitates team coordination. The higher institution must also provide the physical resources that facilitate teamwork and lecturers should try to make researchers perceive the benefits of working in teams.

However, there is no evidence that conflict does arise in university student's team effectiveness in this study. The concern may not be the presence of task conflict but protecting against inadequate conflict management practices being shaped during group training and transmitted to professional practice. Consequently, training and exercise through coursework on conflict management practices might be useful earlier to the start of team activities in higher education settings. Other outcomes of the study also reveal that personality characteristics are not a significant element with respect to team effectiveness outcomes. In sum, another study in different Malaysian universities needs to progress actual teams to investigate the personality-type works of a student group and support their team members know their own attributes.

\section{Funding Information}

The authors have no support or funding to report.

\section{Author's Contributions}

Jeffrey Lawrence D'Silva: Participated in all experiments, coordinated the data-analysis and contributed to the writing of the manuscript.

Seyedali Ahrari: Participated in all experiments, coordinated the data-analysis and contributed to the writing of the manuscript.

\section{Ethics}

This article is original and contains unpublished material. The corresponding author confirms that all of the other authors have read and approved the manuscript and no ethical issues involved.

\section{References}

Adams, S., 1999. An investigation of the attributes contributing to team effectiveness of engineering and science faculty. Proceedings of the 29th Annual Frontiers in Education Conference, Nov. 10-13, IEEE Xplore Press, Lincoln, NE, pp: 12A5/8-12A511. DOI: 10.1109/FIE.1999.839275
Adams, S.G., 2001. The effectiveness of the e-team approach to invention and innovation. J. Eng. Educ., 90: 597-600.

DOI: $10.1002 / \mathrm{j} .2168-9830.2001 . t b 00645 . \mathrm{x}$

Alavi, S.B. and J. McCormick, 2008. The roles of perceived task interdependence and group members' interdependence in the development of collective efficacy in university student group contexts. Briti. J. Educ. Psychol., 78: 375-393. DOI: $10.1348 / 000709907 X 240471$

Allen, N.J. and T.D. Hecht, 2004. The 'romance of teams': Toward an understanding of its psychological underpinnings and implications. J. Occupat. Organ. Psychol., 77: 439-461. DOI: $10.1348 / 0963179042596469$

Arthur, W., B.D. Edwards, S.T. Bell, A.J. Villado and W. Bennett, 2005. Team task analysis: Identifying tasks and jobs that are team based. Hum. Factors: J. Hum. Factors Ergonom. Society, 47: 654-669. DOI: $10.1518 / 001872005774860087$

Aubé, C., V. Rousseau, C. Mama and E.M. Morin, 2009. Counterproductive behaviors and psychological well-being: The moderating effect of task interdependence. J. Bus. Psychol., 24: 351-361. DOI: $10.1007 / \mathrm{s} 10869-009-9113-5$

Balkundi, P. and D.A. Harrison, 2006. Ties, leaders and time in teams: Strong inference about network structure's effects on team viability and performance. Acad. Manage. J., 49: 49-68. DOI: 10.5465/AMJ.2006.20785500

Barki, H. and J. Hartwick, 2004. Conceptualizing the construct of interpersonal conflict. Int. J. Conflict Manage., 15: 216-244. DOI: 10.1108/eb022913

Barrick, M.R. and M.K. Mount, 1991. The Big Five personality dimensions and job performance: A meta-analysis. Personnel Psychol., 44: 1-26. DOI: 10.1111/j.1744-6570.1991.tb00688.x

Barrick, M.R., G.L. Stewart, M.J. Neubert and M.K. Mount, 1998. Relating member ability and personality to work-team processes and team effectiveness. J. Applied Psychol., 83: 377-391. DOI: $10.1037 / 0021-9010.83 .3 .377$

Behera, S. and A.K. Bhardwaj, 2015. An empirical study on the effect of widowhood on personality. Online J. Multidisciplinary Res., 1: 6-11.

Bono, J.E., T.L. Boles, T.A. Judge and K.J. Lauver, 2002. The role of personality in task and relationship conflict. J. Personality, 70: 311-344. DOI: $10.1111 / 1467-6494.05007$

Bradley, B.H., A.C. Klotz, B.E. Postlethwaite and K.G. Brown, 2013. Ready to rumble: How team personality composition and task conflict interact to improve performance. J. Applied Psychol., 98: 385-392. DOI: $10.1037 / \mathrm{a} 0029845$ 
Bradley, B.H., B.E. Postlethwaite, A.C. Klotz, M.R. Hamdani and K.G. Brown, 2012. Reaping the benefits of task conflict in teams: The critical role of team psychological safety climate. J. Applied Psychol., 97: 151-158. DOI: 10.1037/a0024200

Browne, M.W., 1984. Asymptotically distribution-free methods for the analysis of covariance structures. Brit. J. Math. Stat. Psychol., 37: 62-83. DOI: $10.1111 / \mathrm{j} .2044-8317.1984 . t b 00789 . \mathrm{x}$

Byrne, B.M., 2006. Structural Equation Modeling with EQS: Basic Concepts, Applications and Programming. 1st Edn., Lawrence Erlbaum Associates, Mahwah, NJ, ISBN-10: 0805841253, pp: 440.

Byrne, B.M., 2010. Structural Equation Modeling with AMOS: Basic Concepts, Applications and Programming. 2nd Edn., Routledge, New York, ISBN-10: 0805863729, pp: 396.

Chau, P.Y. and P.J.H. Hu, 2001. Information technology acceptance by individual professionals: A model comparison approach. Decision Sci., 32: 699-719. DOI: 10.1111/j.1540-5915.2001.tb00978.x

Chau, P.Y.K., 1997. Reexamining a model for evaluating information center success using a structural equation modeling approach. Decision Sci., 28: 309-334. DOI: $10.1111 / \mathrm{j} .1540-5915.1997 . t b 01313 . x$

Cohen, S.G., G.E. Ledford and G.M. Spreitzer, 1996. A predictive model of self-managing work team effectiveness. Hum. Relati., 49: 643-676. DOI: $10.1177 / 001872679604900506$

Colquitt, J., J.A. Lepine and M.J. Wesson, 2009. Organizational Behavior: Improving Performance and Commitment in the Workplace. 3rd Edn., McGrawHill Education, New York, ISBN-10: 007802935X, pp: 632.

Curşeu, P.L. and H. Pluut, 2013. Student groups as learning entities: The effect of group diversity and teamwork quality on groups' cognitive complexity. Stud. Higher Educ., 38: 87-103. DOI: $10.1080 / 03075079.2011 .565122$

De Dreu, C.K.W., 2014. Negotiating deals and settling conflict can create value for both sides. Policy Insights Behav. Brain Sci., 1: 156-163. DOI: $10.1177 / 2372732214549016$

Edwards, B.D., E.A. Day, W. Arthur Jr and S.T. Bell, 2006. Relationships among team ability composition, team mental models and team performance. J. Applied Psychol., 91: 727-736. DOI: 10.1037/0021-9010.91.3.727

Gabelica, C., P. Van den Bossche, M. Segers and W. Gijselaers, 2012. Feedback, a powerful lever in teams: A review. Educ. Res. Rev., 7: 123-144. DOI: 10.1016/j.edurev.2011.11.003

Hackman, J.R., 1990. Groups that Work (and those that don't): Creating Conditions for Effective Teamwork. 1st Edn., Jossey-Bass, San Francisco, ISBN-10: 1555421873, pp: 512.
Hair, J.F., W.C. Black, B.J. Babin and R.E. Anderson, 2013. Multivariate data analysis. NJ: Pearson, Englewood Cliffs.

Hambrick, D.C., S.E. Humphrey and A. Gupta, 2015. Structural interdependence within top management teams: A key moderator of upper echelons predictions. Strategic Manage. J., 36: 449-461. DOI: $10.1002 / \mathrm{smj} .2230$

Hancock, G.R. and R.O. Mueller, 2004. Path Analysis. In: Thousand Oaks, Lewis-Beck, M., A. Brymann and T.F. Liao (Eds.), CA: Sage, pp: 802-806.

Harrison, D.A., K.H. Price, J.H. Gavin and A.T. Florey, 2002. Time, teams and task performance: Changing effects of surface- and deep-level diversity on group functioning. Acad. Manage. J., 45: 1029-1045. DOI: $10.2307 / 3069328$

Ho, R., 2006. Handbook of Univariate and Multivariate Data Analysis and Interpretation with SPSS. 1st Edn., CRC Press, ISBN-10: 1420011111, pp: 424.

Hogan, J. and B. Holland, 2003. Using theory to evaluate personality and job-performance relations: A socioanalytic perspective. J. Applied Psychol., 88: 100-112. DOI: 10.1037/0021-9010.88.1.100

$\mathrm{Hu}$, L. and P.M. Bentler, 1999. Cutoff criteria for fit indexes in covariance structure analysis: Conventional criteria versus new alternatives. Eq. Model. Multidisciplinary J., 6: 1-55. DOI: $10.1080 / 10705519909540118$

Jehn, K.A., 1994. Enhancing effectiveness: an investigation of advantages and disadvantages of value-based intragroup conflict. Int. J. Conflict Manage., 5: 223-238. DOI: 10.1108/eb022744

Jehn, K.A., 1995. A multimethod examination of the benefits and detriments of intragroup conflict. Admin. Sci. Q., 40: 256-282. DOI: 10.2307/2393638

Jehn, K.A., 1997. A qualitative analysis of conflict types and dimensions in organizational groups. Admin. Sci. Q., 42: 530-557. DOI: 10.2307/2393737

Jehn, K.A. and J.A. Chatman, 2000. The influence of proportional and perceptual conflict composition on team performance. Int. J. Conflict Manage., 11: 56-73. DOI: $10.1108 / \mathrm{eb} 022835$

John, O.P. and S. Srivastava, 1999. The Big-Five trait Taxonomy: History, Measurement and Theoretical Perspectives. In: Handbook of Personality: Theory and Research, Pervin, L.A. and O. P. John (Eds.), Elsevier, New York, ISBN-10: 1572304839, pp: 102-138.

Kichuk, S.L. and W.H. Wiesner, 1998. Work teams: Selecting members for optimal performance. Canad. Psychol. Psychol. Canadienne, 39: 23-32. DOI: $10.1037 / \mathrm{h} 0086792$

Kinicki, A., 2007. Organizational Behavior: Core Concepts. 1st Edn., McGraw-Hill Education, Boston, ISBN-10: 0073530298, pp: 384. 
Kirkman, B.L., J.E. Mathieu, J.L. Cordery, B. Rosen and M. Kukenberger, 2011. Managing a new collaborative entity in business organizations: understanding organizational communities of practice effectiveness. J. Applied Psychol., 96: 1234-1245. DOI: $10.1037 / \mathrm{a} 0024198$

Kline, R.B., 2005. Principles and Practice of Structural Equation Modeling. 1st Edn., Guilford Publications, New York, ISBN-10: 1462523358, pp: 534.

Kline, R.B., 2010. Principles and Practice of Structural Equation Modeling. 3rd Edn., Guilford Press, New York, ISBN-10: 1606238787, pp: 427.

Koh, E. and J. Lim, 2012. Using online collaboration applications for group assignments: The interplay between design and human characteristics. Comput. Educ., 59: 481-496.

DOI: $10.1016 /$ j.compedu.2012.02.002

Langfred, C.W., 2007. The downside of selfmanagement: A longitudinal study of the effects $\mathrm{tf}$ conflict on trust, autonomy and task interdependence in self-managing teams. Acad. Manage. J., 50: 885-900.

DOI: 10.5465/AMJ.2007.26279196

Lee, C.C., Y.H. Lee, H.H. Chen and P.S. Hsieh et al., 2014. The impact of team diversity, task interdependence, team conflict and team cooperation on job performance: Using real estate Brokers as examples. Int. J. Manage. Sustainab., 3: 415-432.

Marks, M.A., S.J. Zaccaro and J.E. Mathieu, 2000. Performance implications of leader briefings and team-interaction training for team adaptation to novel environments. J. Applied Psychol., 85: 971-986. DOI: 10.1037/0021-9010.85.6.971

Markus, K.A., 2012. Principles and practice of structural equation modeling by Rex B. Kline. Struct. Eq. Model. Multidisciplinary J., 19: 509-512. DOI: $10.1080 / 10705511.2012 .687667$

Molleman, E., 2009. Attitudes toward flexibility the role of task characteristics. Group Organ. Manage., 34: 241-268. DOI: $10.1177 / 1059601108330090$

Puck, J. and U. Pregernig, 2014. The effect of task conflict and cooperation on performance of teams: Are the results similar for different task types? Eur. Manage. J., 32: 870-878.

DOI: $10.1016 /$ j.emj.2014.03.007

Putnam, L.L., 1994. Productive conflict: Negotiation as implicit coordination. Int. J. Conflict Manage., 5: 284-298. DOI: $10.1108 / \mathrm{eb} 022748$

Sackett, P.R. and P.T. Walmsley, 2014. Which personality attributes are most important in the workplace? Perspectives Psychol. Sci., 9: 538-551. DOI: $10.1177 / 1745691614543972$

Salgado, J.F., 1997. The five factor model of personality and job performance in the European Community. J. Applied Psychol., 82: 30-43.

DOI: $10.1037 / 0021-9010.82 .1 .30$
Sander, P.C., R.R.A. van Doorn, J. van der Pal and F.R.H. Zijlstra, 2015. Team adaptation to an unforeseen system failure: Limits of the potential aids of shared knowledge and standardized communication. Eur. J. Work Organ. Psychol., 24: 1-16. DOI: 10.1080/1359432X.2015.1006199

Sarason, I.G., 1984. Stress, anxiety and cognitive interference: Reactions to tests. J. Personality Social Psychol., 46: 929-938.

Shah, P.P. and K.A. Jehn, 1993. Do friends perform better than acquaintances? The interaction of friendship, conflict and task. Group Decision Negotiat., 2: 149-165. DOI: 10.1007/BF01884769

Somech, A., 2008. Managing conflict in school teams: The impact of task and goal interdependence on conflict management and team effectiveness. Educ. Admin. Q., 44: 359-390. DOI: $10.1177 / 0013161 \mathrm{X} 08318957$

Somech, A., H.S. Desivilya and H. Lidogoster, 2009. Team conflict management and team effectiveness: The effects of task interdependence and team identification. J. Organ. Behavior, 30: 359-378. DOI: $10.1002 /$ job.537

Troth, A.C., P.J. Jordan, S.A. Lawrence and H.H.M. Tse, 2012. A multilevel model of emotional skills, communication performance and task performance in teams. J. Organ. Behavior, 33: 700-722.

DOI: $10.1002 /$ job.785

Van der Vegt, G.S. and E. Van de Vliert, 2002. Intragroup interdependence and effectiveness: Review and proposed directions for theory and practice. J. Managerial Psychol., 17: 50-67. DOI: $10.1108 / 02683940210415924$

Van Der Vegt, G.S., B.J.M. Emans and E. Van de Vliert, 2001. Patterns of interdependence in work teams: A two-level investigation of the relations with job and team satisfaction. Personnel Psychol., 54: 51-69. DOI: $10.1111 / \mathrm{j} .1744-6570.2001 . t b 00085 . x$

Van Der Vegt, G.S., E. Van de Vliert and X. Huang, 2005. Location-level links between diversity and innovative climate depend on national power distance. Acad. Manage. J., 48: 1171-1182. DOI: 10.5465/AMJ.2005.19573116

Wageman, R., 1995. Interdependence and group effectiveness. Admin. Sci. Q., 40: 145-180. DOI: $10.2307 / 2393703$

Wageman, R. and G. Baker, 1997. Incentives and cooperation: The joint effects of task and reward interdependence on group performance. J. Organ. Behavior, 18: 139-158. DOI: 10.1002/(SICI)10991379(199703)18:2<139::AID-JOB791>3.0.CO;2-R

Wanous, M., B. Procter and K. Murshid, 2009. Assessment for learning and skills development: The case of large classes. Eur. J. Eng. Educ., 34: 77-85. DOI: $10.1080 / 03043790902721462$ 